\title{
The bone marrow microenvironment enhances multiple myeloma progression by exosome-mediated activation of myeloid-derived suppressor cells
}

\author{
Jinheng Wang ${ }^{1}$, Kim De Veirman ${ }^{1}$, Nathan De Beule ${ }^{1}$, Ken Maes ${ }^{1}$, Elke De Bruyne ${ }^{1}$, \\ Els Van Valckenborgh ${ }^{1}$, Karin Vanderkerken ${ }^{1, *}$, Eline Menu ${ }^{1, *}$ \\ ${ }^{1}$ Department of Hematology and Immunology, Myeloma Center Brussels, Vrije Universiteit Brussels (VUB), Brussels, Belgium \\ "These authors have equally contributed to this work \\ Correspondence to: Eline Menu, e-mail: Eline.Menu@vub.ac.be \\ Keywords: multiple myeloma, bone marrow stromal cells, exosomes, myeloid-derived suppressor cells, immunosuppression \\ Received: July 17, 2015 \\ Accepted: October 23, 2015 \\ Published: November 02, 2015
}

\section{ABSTRACT}

Exosomes, extracellular nanovesicles secreted by various cell types, modulate the bone marrow (BM) microenvironment by regulating angiogenesis, cytokine release, immune response, inflammation, and metastasis. Interactions between bone marrow stromal cells (BMSCs) and multiple myeloma (MM) cells play crucial roles in MM development. We previously reported that BMSC-derived exosomes directly promote MM cell growth, whereas the other possible mechanisms for supporting MM progression by these exosomes are still not clear. Here, we investigated the effect of BMSC-derived exosomes on the MM BM cells with specific emphasis on myeloidderived suppressor cells (MDSCs). BMSC-derived exosomes were able to be taken up by MM MDSCs and induced their expansion in vitro. Moreover, these exosomes directly induced the survival of MDSCs through activating STAT3 and STAT1 pathways and increasing the anti-apoptotic proteins $\mathrm{Bcl}-\mathrm{xL}$ and $\mathrm{Mcl}-1$. Inhibition of these pathways blocked the enhancement of MDSC survival. Furthermore, these exosomes increased the nitric oxide release from MM MDSCs and enhanced their suppressive activity on $T$ cells. Taken together, our results demonstrate that BMSC-derived exosomes activate MDSCs in the BM through STAT3 and STAT1 pathways, leading to increased immunosuppression which favors MM progression.

\section{INTRODUCTION}

Exosomes are nanometric membrane vesicles derived from late endosomes, released by normal and tumor cells. Exosomes mainly function as mediators of local and systemic communication by transferring mRNAs, microRNAs, and proteins [1]. Uptake of exosomes by recipient cells is mainly carried out through direct fusion with the plasma membrane or endocytic pathways [2]. The exosome, as a communicator, can educate the bone marrow (BM) microenvironment by targeting various cell types in the $\mathrm{BM}$, including macrophages [3], dendritic cells [3], B cells [4, 5], T cells $[4,6]$, mesenchymal stem cells (MSCs) [7], BM stromal cells (BMSCs) [8], myeloid-derived suppressor cells (MDSCs) [9, 10], as well as tumor cells [8, 11]. Compelling studies reported that exosomes secreted by $\mathrm{BM}$-derived cells or tumor cells maintain and regulate the microenvironment by affecting angiogenesis [12-14], cytokine secretion [8], cell differentiation [15], immune response [1, 16], inflammation [17], and metastasis [18] in the BM.

Multiple myeloma (MM) is a plasma cell malignancy which is predominantly localized in the BM. MM progression largely relies on support from the BM microenvironment, which is mainly composed of stromal cells, endothelial cells, immune cells, and extracellular matrix [19]. It is well studied that stromal cells directly facilitate the MM progression and drug resistance through cell-to-cell contact and cytokine stimulation [20]. In addition, BM-MSCs or BMSCs interact with dendritic cells [21], NK cells [22, 23], and MDSCs [24], to modulate the BM microenvironment, which may indirectly favor tumor growth. We previously reported that exosomes derived from BMSCs could mediate the communication between stromal cells and 
MM cells and promote MM progression [11]. However, indirect approaches for promoting MM growth through regulation of the $\mathrm{BM}$ microenvironment by BMSCderived exosomes (BMSC exosomes) have not been studied.

MDSCs are immature myeloid cells that are negative regulators of the immune response and which accumulate in secondary lymphoid tissue and in the tumor microenvironment during tumor development $[25,26]$. Activated MDSCs promote tumor growth and invasion, immunosuppression, and host immune evasion by suppressing lymphocyte activation and antigen recognition [27]. MDSC expansion and activation are mainly mediated by growth factors secreted by tumor cells, tumor stromal cells, activated $\mathrm{T}$ cells and macrophages, and pathogeninfected cells [28]. Exosomes released by cancer cells are also involved in the activation and expansion of MDSC, leading to enhanced immunosuppression which contributes to tumor development $[10,29]$. Nevertheless, very little is known about MDSC activation mediated by exosomes derived from other cells in the $\mathrm{BM}$ microenvironment.

Immunosuppressive MDSCs can be observed in MM patients and mouse models [30-32]. Our previous studies showed that MDSCs from 5T33MM mice have a higher suppressive capacity than those from naive mice [31]. In the BM microenvironment, stromal cells have been shown to contribute to the expansion and activation of MDSCs through secreting hepatocyte growth factor (HGF) and activating the STAT3 pathway [24]. However, in the MM BM microenvironment, the effects of exosomes released from stromal cells on MDSC activation are still unknown. In the present study, we explored the roles of BMSC exosomes in the expansion and activation of MDSC using the murine 5T33MM model.

\section{RESULTS}

\section{Uptake of BMSC exosomes by 5T33MM BM cells}

We and others have previously shown that exosomes can mediate the communication between BMSCs and MM cells and the uptake of exosomes by recipient cells is mainly observed through membrane labeling $[11,33]$. However, the MM BM microenvironment contains, besides MM cells, various other cell types and here we wished to determine whether BMSC exosomes can be taken up by all these cells. First, to confirm uptake, we labeled the membrane or content of BMSC exosomes using membrane tracker DIO or cell-permeant nucleic acid stains RGFCS respectively and cultured them with 5T33MMvt cells for different time points (Supplementary Figure S1A-S1D). Gradual increase over time of $\mathrm{DIO}^{+}$ and $\mathrm{RGFCS}^{+}$cells, as well as enhanced fluorescent signal, were detected after co-culture, suggesting two different ways to take up exosomes by recipient cells, namely membrane fusion and endocytosis (Figure 1A). Next, whole 5T33MM BM was cultured with DIO- or RGFCS-labeled BMSC exosomes and the uptake of exosomes by different subpopulations in the BM cells was determined. Uptake of DIO-labeled exosomes was detected on average in $70 \%$ of the BM cells and almost all the cells took up RGFCS-labeled exosomes after 24 hours (Figure $1 \mathrm{~B}$ and $1 \mathrm{C})$. MM $\left(3 \mathrm{H} 2^{+} \mathrm{CD} 11 \mathrm{~b}-\right)$ cells and $\mathrm{CD} 11 \mathrm{~b}^{+}$ cells, which mainly are MDSCs, took up more DIO- or RGFCS-labeled exosomes than the rest of the BM cells $\left(3 \mathrm{H} 2{ }^{-} \mathrm{CD} 11 b^{-}\right)$(Figure 1B and $\left.1 \mathrm{C}\right)$. Moreover, the mean fluorescence intensity of DIO or RGFCS in CD11 b cells was significantly higher than in the other subpopulations, as well as in total BM cells (Supplementary Figure S1E and S1F), suggesting a greater capacity for taking up
A

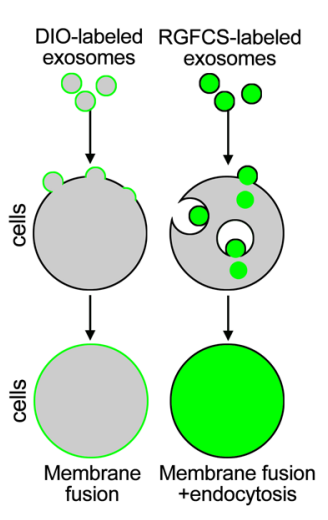

B

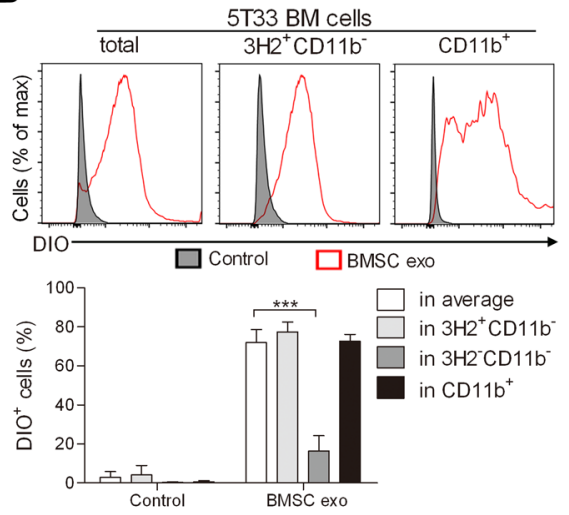

C

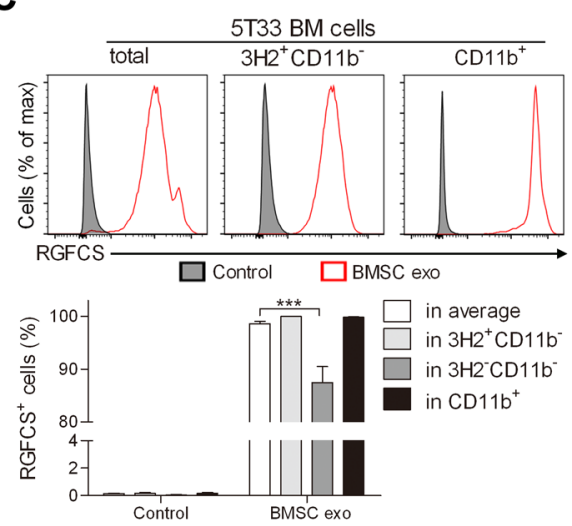

Figure 1: Mechanisms of uptake of BMSC exosomes by MM BM cells. A. Diagram illustrating how DIO- or RGFCS-labeled exosomes are taken up by cells. BM cells obtained from diseased 5T33MM mice $(n=3)$ were cultured with B. DIO- or C. RGFCS-labeled

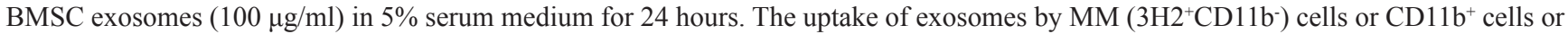
$3 \mathrm{H} 2-\mathrm{CD} 11 \mathrm{~b}$ - cells was determined by flow cytometry after anti-3H2-APC and anti-CD11b-PE-Cy7 staining. DIO or RGFCS positive cells were regarded as the cells that have already taken up exosomes. $* * *=p<0.001$. 
exosomes. These results indicate that BMSC exosomes are not only taken up by MM cells, but also by the other BM cells such as MDSCs.

\section{BMSC exosomes promote the survival of the whole 5T33MM BM cells in vitro}

Since BMSC exosomes can be taken up by all the $\mathrm{BM}$ cells, we next determined the effect of these exosomes on the different cells. BM cells were isolated from mice 2 weeks (intermediate stage of MM) or 3 weeks (late stage of MM) after inoculation with 5T33MM cells and cultured with BMSC exosomes. After 24 hours of co-culture, subpopulations in the BM cells were altered (Figure 2A) and the survival of the BM cells obtained from week 2 or week 35 T33MM mice was significantly enhanced (Figure 2B). The number of living $\mathrm{MM}\left(3 \mathrm{H} 2^{+} \mathrm{CD} 11 \mathrm{~b}^{-}\right)$ and $3 \mathrm{H} 2{ }^{-C D} 11 b^{-}$cells was significantly higher in both week 2 and week 3 5T33MM BM (Figure 2C and 2D), whereas the enhanced survival of $\mathrm{CD}_{11 b^{+} \text {cells was }}$ mostly observed in week 3 5T33MM BM (Figure 2D). Moreover, the mean fluorescence intensity of CD11b

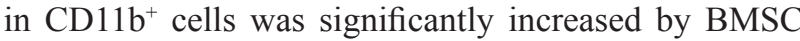
exosomes (Supplementary Figure S2A). Long-term cultures (11 days) demonstrated that BMSC exosomes could promote the survival of the total BM (Figure 2E) in which the viability of the MM cells was also augmented (Supplementary Figure S2B). Moreover, the survival and
A

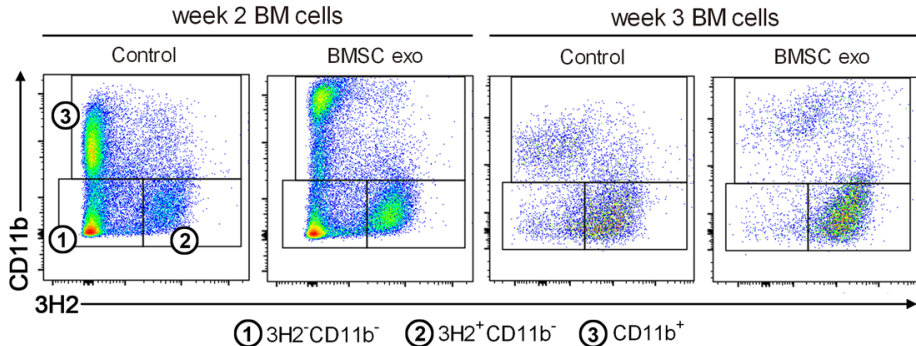

B

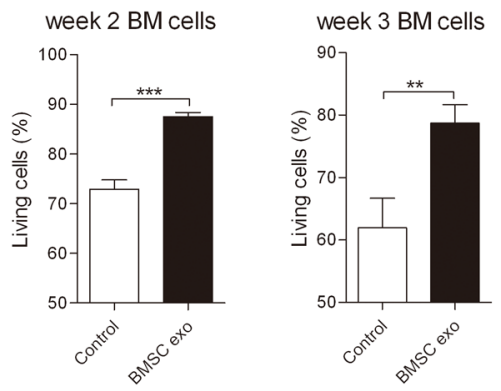

C

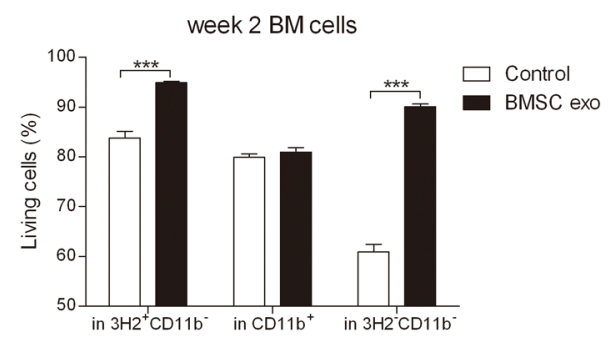

$\mathbf{E}$

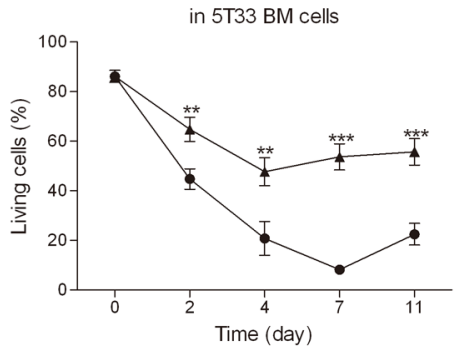

$\mathbf{F}$

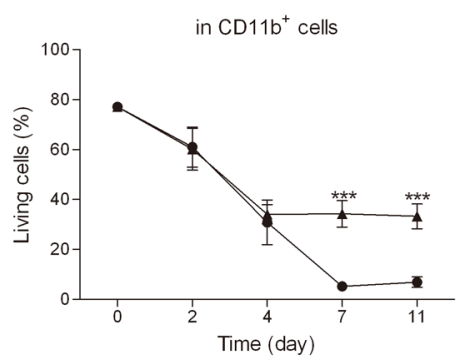

D

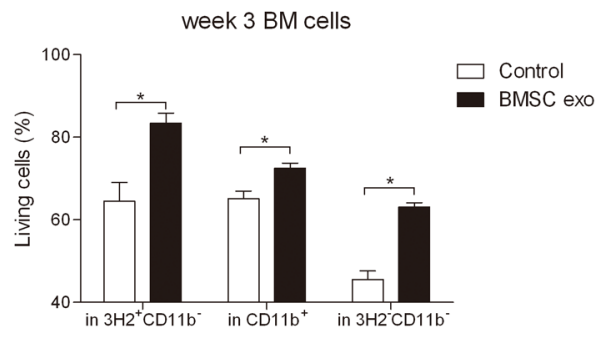

G

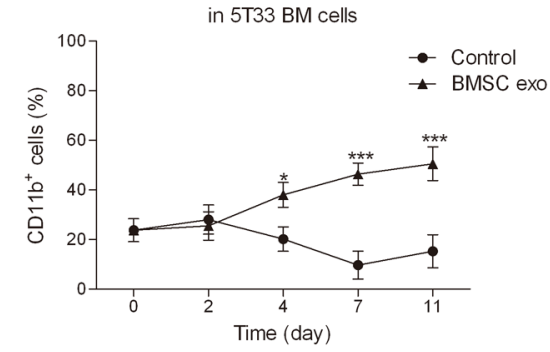

Figure 2: BMSC exosomes promote the survival of BM cells obtained from 5T33MM mice in intermediate and late stage of MM. BM cells isolated from mice inoculated with 5T33MM cells for 2 weeks (week 2 BM cells, $n=4$ ) or 3 weeks (week $3 \mathrm{BM}$ cells, $n=3$ ) were cultured with BMSC exosomes (BMSC exo, $100 \mu \mathrm{g} / \mathrm{ml}$ ) in medium with $5 \%$ serum for 24 hours and then the cells were stained with anti-3H2-APC, anti-CD11b-PE-Cy7, and Annexin V-FITC. A. The gating of the subpopulations 3H2-CD11b$3 \mathrm{H} 2^{+} \mathrm{CD} 11 \mathrm{~b}$, and $\mathrm{CD} 11 \mathrm{~b}^{+}$cells in week 2 or week $35 \mathrm{~T} 33 \mathrm{MM} \mathrm{BM}$ cells after co-culturing with exosomes is shown. B-D. The percentage of living (Annexin $\mathrm{V}^{-}$) cells after culturing with or without BMSC exosomes was analyzed in: week 2 or week 3 BM population (B); MM $\left(3 \mathrm{H} 2^{+} \mathrm{CD} 11 \mathrm{~b}^{-}\right), \mathrm{CD} 11 \mathrm{~b}^{+}$cells, and $3 \mathrm{H} 2{ }^{-} \mathrm{CD} 11 \mathrm{~b}^{-}$in week $2(\mathrm{C})$ or week $3 \mathrm{BM}$ cells (D). E-G. BM cells isolated from week $35 \mathrm{~T} 33 \mathrm{MM}$ mice $(n=3)$ were cultured with BMSC exosomes (BMSC exo, $50 \mu \mathrm{g} / \mathrm{ml})$ in $5 \%$ serum medium for 11 days. BMSC exosomes were added 3 times a week and the medium was refreshed every week. At different time points, the cells were stained with anti-3H2-APC, anti-CD11bPE-Cy7, and Annexin V-FITC. (E) The change of living cells in whole BM cells at indicated time points was measured. (F) The change of living cells in $\mathrm{CD} 11 \mathrm{~b}^{+}$population and $(\mathrm{G})$ the percentage of $\mathrm{CD} 11 \mathrm{~b}^{+}$cells were also evaluated at different time points by flow cytometry. * $=p<0.05, * *=p<0.01, * * *=p<0.001$. 
percentage of $\mathrm{CD} 11 \mathrm{~b}^{+}$cells were significantly increased after respectively 4 and 7 days of co-culture (Figure $2 \mathrm{~F}$ and $2 \mathrm{G})$. Finally, the presence of CD11b on CD11b cells was gradually increased by exosomes until day 7 (Supplementary Figure S2C). These data suggest that BMSC exosomes not only affect MM cells, but also MDSCs.

\section{BMSC exosomes directly promote the survival of MDSC}

To investigate direct effect of the BMSC exosomes on the MDSC, CD11b+ cells were sorted from the BM of naive or 5T33MM mice by MACS and the purity was confirmed (Supplementary Figure S3). 5\% serum or serum free conditions were used to determine if BMSC exosomes could affect MDSCs in the presence or absence of growth factors. BMSC exosomes significantly increased the cell viability of naive and 5 T33 CD11 $\mathrm{b}^{+}$ cells in 5\% serum medium as measured by a luminescent viability assay (Figure 3A). Moreover, in serum free conditions, BMSC exosomes increased the cell viability of naive and $5 \mathrm{~T} 33 \mathrm{CD} 11 \mathrm{~b}^{+}$cells up to 10 times and 7 times respectively (Figure $3 \mathrm{~B}$ ). These data indicate that BMSC exosomes promote MDSC expansion even in the presence of other growth factors. To determine whether this enhanced viability was a result of reduced apoptosis, the percentage of living (Annexin $\mathrm{V}^{-}$) naive and $5 \mathrm{~T} 33$ $\mathrm{CD}_{11} \mathrm{~b}^{+}$cells was measured by flow cytometry. Figure $3 \mathrm{C}$ and $3 \mathrm{D}$ demonstrate that exosomes increase the percentage of living cells up to 2 fold in $5 \%$ serum or serum free conditions, indicating that reduced apoptosis is not the sole mediator of MDSC expansion.

\section{BMSC exosomes mainly promote the survival of Ly6G $^{\text {low }}$ Ly6C $^{+}$MDSCs}

Previously, MDSCs have been identified as $\mathrm{CD}_{11 \mathrm{~b}^{+} \mathrm{Gr}-1^{+}}$cells in mice and two subtypes of MDSC, namely granulocytic MDSCs expressing

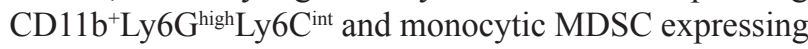
CD $11 b^{+}{\text {Ly } 6 G^{\text {low }}}$ Ly6C $C^{+}$, have been characterized, these subpopulation have distinct phenotypes, morphology, and immunosuppressive mechanisms [31, 34]. As BMSC exosomes directly promote MDSC survival, we next determined the effect of these exosomes on the MDSC subpopulations. After culture with BMSC exosomes, MACS-sorted naive and 5T33 CD11 $\mathrm{b}^{+}$cells had 4 times more CD11b expression on their membrane and Gr-1 expression was also slightly increased (Figure $4 \mathrm{~A}$ ), whereas the percentage of $\mathrm{CD} 11 \mathrm{~b}^{+} \mathrm{Gr}-1^{+}$cells was not changed (Supplementary Figure S4A and S4B). An average of $60 \% \mathrm{CD} 11 \mathrm{~b}^{+}$cells expressed a very high

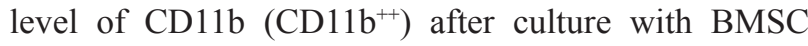
exosomes while only $10 \% \mathrm{CD} 11 \mathrm{~b}^{++}$cells were detected in the control (Supplementary Figure S4C). We next determined the composition of the $\mathrm{Ly} 6 \mathrm{G}^{\text {high }} \mathrm{Ly} 6 \mathrm{C}^{\text {int }}$ and $\mathrm{Ly}_{6 \mathrm{G}}{ }^{\text {low }} \mathrm{Ly} 6 \mathrm{C}^{+}$subpopulations in naive and tumor bearing mice and found a clear difference with $\mathrm{MM}$ mice having more $\mathrm{CD} 11 \mathrm{~b}^{+} \mathrm{Ly} 6 \mathrm{G}^{\text {low }} \mathrm{Ly} 6 \mathrm{C}^{+}$cells (Figure 4B). This is in line with our previous publication [31]. To determine whether BMSC exosomes are involved in this process, we co-cultured them with naive or $5 \mathrm{~T} 33$ MDSCs. BMSC exosomes could enhance the survival of both subpopulations and more survival of Ly $6 \mathrm{G}^{\text {low }} \mathrm{Ly} 6 \mathrm{C}^{+}$ MDSCs, which is composed of inflammatory or classical monocytes, immature myeloid cells, and eosinophils [31], was observed when compared with granulocytic MDSCs (Ly6G ${ }^{\text {high }}$ Ly6C ${ }^{\text {int }}$ ) (Figure 4C and 4D). These results demonstrate that BMSC exosomes promote the survival of all MDSCs but have a stronger impact on $\mathrm{Ly} 6 \mathrm{G}^{\text {low }} \mathrm{Ly} 6 \mathrm{C}^{+}$ MDSCs.

\section{BMSC exosomes activate STAT1 and STAT3 pathways in MDSCs}

Signal transducer and activator of transcription family proteins (STATs), including Stat1, Stat3, and Stat6, are the main regulators of MDSC expansion and activation and activated Stat3 also contributes to cell survival [28]. Since BMSC exosomes promote MDSC survival, activation of Stat1 and Stat 3 in these cells was determined next. BMSC exosomes clearly increased the phosphorylation of Stat1 and Stat3 (p-Stat1 and p-Stat3) in naive and $5 \mathrm{~T} 33 \mathrm{CD} 11 \mathrm{~b}^{+}$cells in both $5 \%$ serum and serum free conditions (Figure 5A and 5B). Elevated protein level

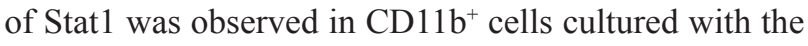
exosomes (Figure 5A and 5B). Two anti-apoptotic proteins Mcl-1 and Bcl-xL, mainly regulated by the STAT3 pathway, were also clearly increased by the exosomes after 24 hours (Figure 5A and 5B).

\section{Inhibition of STAT1 and STAT3 pathways reduce $\mathrm{BMSC}$ exosome effects on MDSC survival}

Several papers have suggested how MDSCs can be activated by tumor cells. Granulocyte/macrophage colony-stimulating factor (GM-CSF) is a soluble factor involved in MDSC activation and our group demonstrated that a blocking antibody of GM-CSF can abrogate MM induced pro-survival effects on MDSCs [25]. Membraneassociated Hsp70 from tumor-derived exosomes has been shown to activate MDSC through STAT3 pathways [29]. Here, we used blocking antibodies to examine the involvement of GM-CSF and Hsp70 in BMSC exosomeinduced effects. However, these two blocking antibodies did not affect $\mathrm{CD}_{1} 1 \mathrm{~b}^{+}$cell viability in the absence or presence of BMSC exosomes, suggesting that exosomeinduced activation of MDSC is independent of GM-CSF and membrane-associated Hsp70 (Supplementary Figure S5A and S5B). Inhibitors of STAT1 and STAT3 pathways were next used to confirm the involvement of these two

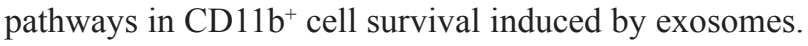


A
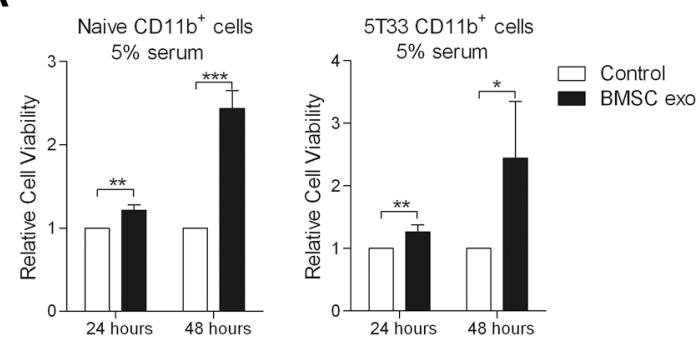

C

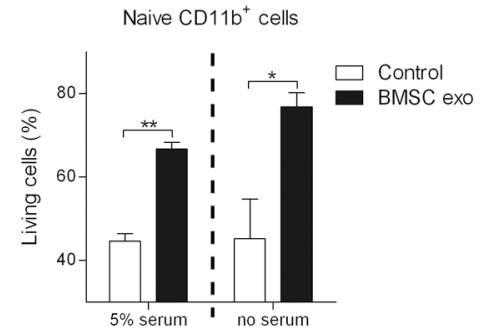

B

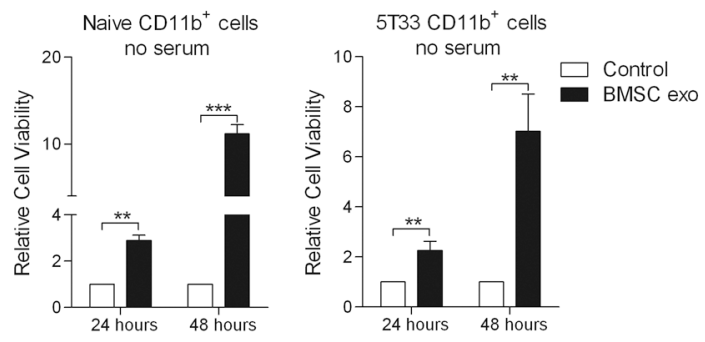

D

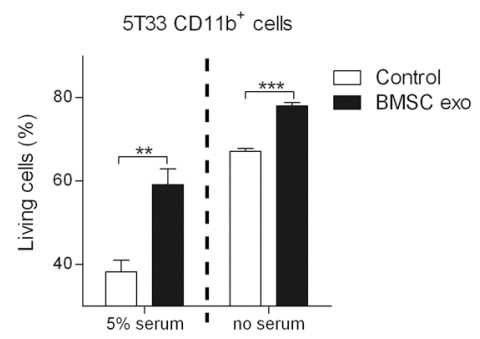

Figure 3: BMSC exosomes induce CD11b+ cell survival. CD11 $\mathrm{b}^{+}$cells isolated from naive $\mathrm{BM}$ (naive $\mathrm{CD} 11 \mathrm{~b}^{+}$cells, $n=3$ ) or 5T33MM BM (5T33 CD11 b cells, $n=3$ ) were cultured with BMSC exosomes (BMSC exo, $100 \mu \mathrm{g} / \mathrm{ml}$ ) in A. $5 \%$ serum or B. serum free (no serum) conditions for 24 or 48 hours, and the cell viability was determined by a luminescent viability assay. C. Naive $(n=3)$ or D. 5 T33

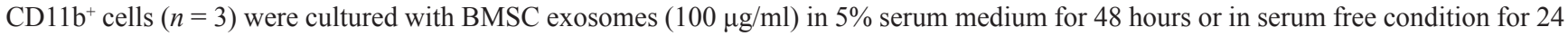
hours, and the living (Annexin V) cells were determined by flow cytometry. ${ }^{*}=p<0.05, * *=p<0.01, * * *=p<0.001$.

A

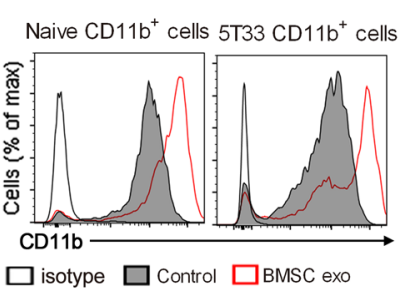

C

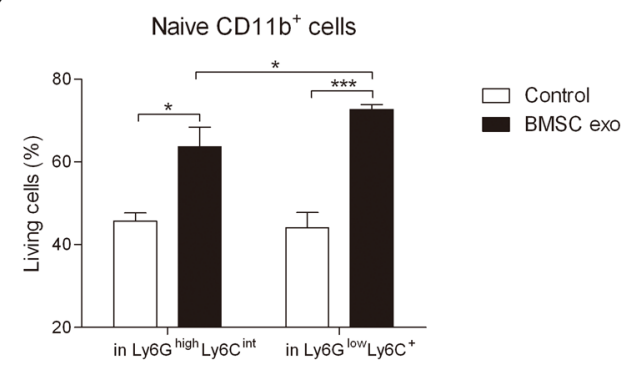

B
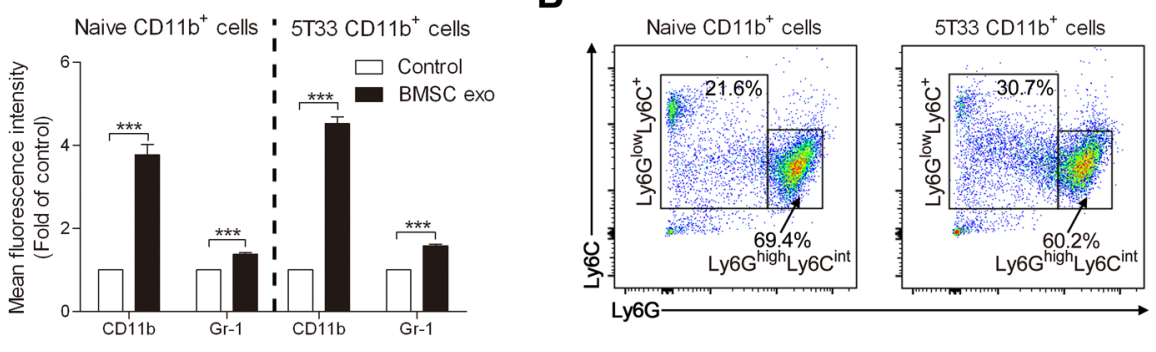

D

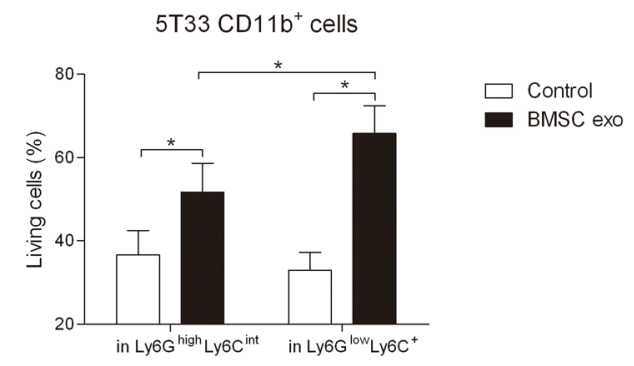

Figure 4: BMSC exosomes mainly induce the survival of CD11 $\mathbf{b}^{+} \mathbf{L y}_{6} \mathbf{G}^{\text {low }} \mathbf{L y 6 C ^ { + }}$ cells. A. Naive $(n=3)$ or $5 \mathrm{~T} 33 \mathrm{CD} 1 \mathrm{~b}^{+}$cells $(n=3)$ were cultured with BMSC exosomes (BMSC exo, $100 \mu \mathrm{g} / \mathrm{ml})$ in $5 \%$ serum medium for 48 hours and then stained with anti-CD11bPE-Cy7 and anti-Gr-1-APC. Mean fluorescence intensities of CD11b and Gr-1 were measured by flow cytometry. B. Subpopulations of naive or $5 \mathrm{~T} 33 \mathrm{CD} 11 \mathrm{~b}^{+}$cells were determined using anti-Ly6G-PE-Cy7 and anti-Ly6C-APC staining. C. Naive $(n=3)$ or D. $5 \mathrm{~T} 33 \mathrm{CD} 11 \mathrm{~b}^{+}$ cells $(n=3)$ were treated with BMSC exosomes $(100 \mu \mathrm{g} / \mathrm{ml})$ in $5 \%$ serum medium for 48 hours and then stained with anti-Ly6G-PE-Cy7, anti-Ly6C-APC, and Annexin V-FITC. The percentages of living (Annexin-V) cells in Ly6G ${ }^{\text {low }}{ }^{-} 66 \mathrm{C}^{+}$and Ly6 $\mathrm{G}^{\text {high }} \mathrm{Ly} 6 \mathrm{C}^{\text {int }}$ subsets were determined by flow cytometry. $*=p<0.05,{ }^{* * *}=p<0.001$. 
The STAT1 inhibitor fludarabine and two STAT3 inhibitors 5,15-DPP and stattic, inhibited $\mathrm{CD}_{11} \mathrm{~b}^{+}$cell viability even in the presence of BMSC exosomes (Figure 6A and 6B). They also significantly suppressed BMSC exosomemediated survival of both naive and 5 T33 CD11b cells (Figure 6C and 6D), confirming the participation of STAT1 and STAT3 pathways in MDSC survival. Fludarabine is a well-used Stat1 inhibitor [35, 36], but it has been shown to affect other pathways such as p53 [37], therefore we examined whether p53 activation was impacted in MDSC. In 5T33 CD11b $\mathrm{b}^{+}$cells, fludarabine reduced the phosphorylation of Stat1 in the presence of BMSC exosomes, whereas p53 and its phosphorylation were not changed (Figure 6E).

\section{BMSC exosomes activate the STAT3 pathway in MDSCs in vivo and enhance their capacity for $T$ cell suppression}

To confirm the uptake of exosomes by MDSC in vivo, RGFCS-labeled BMSC exosomes were intravenously injected into 5T33MM mice and after 24 hours, an increase of mean fluorescence of RGFCS in the BM and $\mathrm{CD}_{11} \mathrm{~b}^{+}$cells was observed (Figure 7A). In addition, in vivo injection of BMSC exosomes increased activation of Stat3 (p-Stat3) in BM CD11b $\mathrm{Br}-1^{+}$cells (Figure 7B). p-Stat1 also showed a non significant $(p=0.057)$ trend to increase in BM MDSCs after injection with exosomes (Figure 7C). Activated MDSCs tend to release more nitric oxide (NO) production which contributes to the inhibition of $\mathrm{T}$ cells [28]. BMSC exosomes increased the release of NO from 5T33 $\mathrm{CD}_{11} \mathrm{~b}^{+}$cells (Figure 7D), whereas NO production was undetectable in naive $\mathrm{CD} 11 \mathrm{~b}^{+}$cells even in the presence of BMSC exosomes (data not shown). Moreover, MDSCs from 5T33MM mice injected with BMSC exosomes exerted a stronger immunosuppressive effect on $\mathrm{T}$ cell proliferation compared to those from 5T33MM mice injected with PBS (Figure 7E).

\section{DISCUSSION}

Activation of MDSC by tumor exosomes has already been investigated in solid tumor models [10, 29], however the influence of exosomes from the surrounding tissue has not been thoroughly examined yet. Since MM develops in the BM, we sought to investigate the effect of BMSCderived exosomes on MDSC activation. Our results have identified BMSC exosomes as novel mediators for MDSC activation which leads to an enhancement of the immunosuppressive function of MDSC in the MM BM. Through culturing of BMSC exosomes with MM BM cells, we demonstrated that these exosomes can be taken up not only by MM cells but also by MDSCs and that these cells are affected in the short and long term. BMSC exosomes directly promote the survival of MDSCs by an enhanced activation of STAT1 and STAT3 pathways. The activated MM MDSCs in the 5T33MM mouse model acquired an enhanced capacity for $\mathrm{T}$ cell suppression which facilitates immune escape of the MM cells. Our work proposes an indirect mechanism for promoting MM progression by BMSC exosomes: exosomes released
A

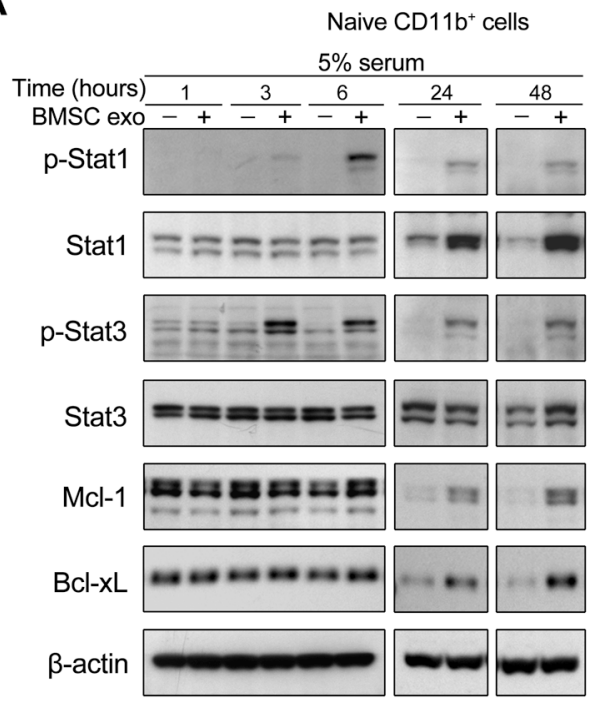

B

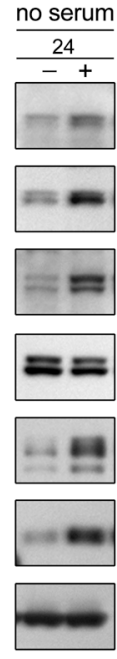

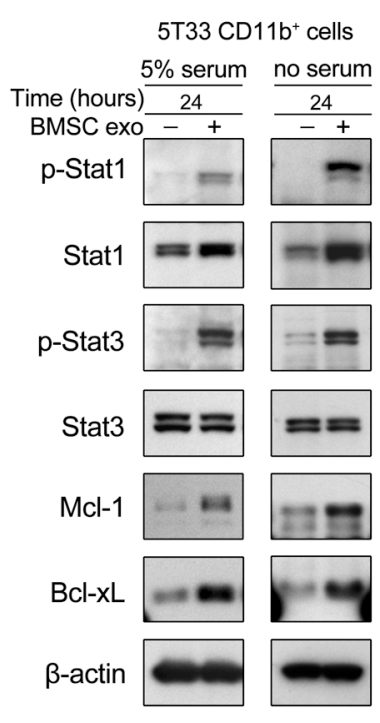

Figure 5: BMSC exosomes activate STAT1 and STAT3 pathways and increase Bcl-xL and Mcl-1 in CD11 ${ }^{+}$cells. A. Naive CD $11 b^{+}$cells were cultured with BMSC exosomes (BMSC exo, $100 \mu \mathrm{g} / \mathrm{ml}$ ) in 5\% serum or serum free (no serum) condition for indicated hours. The total and phosphorylated Stat 1 and Stat3, as well as the expression of Bcl-xL and Mcl-1 were detected using western blot. The analysis of $\beta$-actin protein was included as a loading control. B. $5 \mathrm{~T} 33 \mathrm{CD} 11 \mathrm{~b}^{+}$cells were cultured with BMSC exosomes (100 $\mu \mathrm{g} / \mathrm{ml})$ in $5 \%$ serum or serum free condition for 24 hours. The total and phosphorylated Stat1 and Stat3, as well as Bcl-xL and Mcl-1 were detected using western blot. 
from BMSCs induce MDSC survival and elevate their immunosuppressive capacity, leading to T cell suppression which favors MM development (Figure 8).

By labeling the membrane or content of BMSC exosomes with DIO or RGFCS, we identified that these exosomes can be taken up by all BM cells. Extracellular vesicles, including exosomes and microvesicles, deliver their contents of proteins, RNAs, and lipids through direct fusing with the cell plasma membrane or being endocytosed and internalized by recipient cells [2]. Here, we detected the uptake of both DIO- and RGFCSlabeled exosomes by MM cells, as well as CD11b cells,

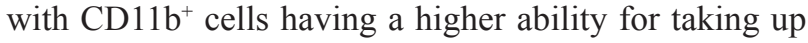
exosomes. These results can be explained by the fact that $\mathrm{CD}_{11} \mathrm{~b}^{+}$cells mainly are MDSCs (because nearly all of them co-express Gr-1) [31] which have bigger membranes than MM cells or other lymphocytes, leading to an increased opportunity for fusing with exosomes.

It has been previously demonstrated that accumulation of activated MDSCs in the BM is observed at early stages of MM and it has been shown that they play a critical role in MM progression by inhibiting $\mathrm{T}$ cell function [30]. However, the mechanisms behind this increase are not completely understood yet. Very few studies have demonstrated the relationship between exosomes and MDSC expansion and they are mainly focused on exosomes secreted from tumor cells which induce immunosuppressive functions in MDSC [10,
29], whereas the effects of exosomes derived from the other cells on MDSC have not been studied. Our finding that BMSC exosomes directly induced survival of MDSC even in the presence of growth factors would emphasize the importance of exosomes derived from non-tumor cells in tumor growth through educating the $\mathrm{BM}$ microenvironment. CD11b can regulate leukocyte adhesion and cell migration [34] and BMSC exosomes dramatically increased its expression on the membrane of MDSC which may lead to the enhancement of their ability to migrate to secondary lymphoid tissue. In mice, two major subsets of MDSCs, namely granulocytic MDSCs and monocytic MDSCs, have been identified [34] and they have different functions in cancer and infectious and autoimmune diseases [28, 34, 38, 39]. BMSC exosomes were able to promote the survival of both subsets and specifically induced more survival of

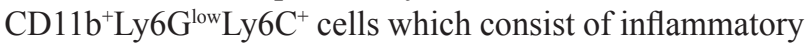
or classical monocytes, immature myeloid cells, and eosinophils. Our group has reported that $\mathrm{CD} 11 \mathrm{~b}^{+} \mathrm{LyG}^{\text {low }}$ cells are increased in 5T33MM BM and that they have a higher immunosuppressive capacity than $\mathrm{CD} 11 \mathrm{~b}^{+} \mathrm{Ly} 6 \mathrm{G}^{\text {high }}$ cells [31]. As a part of the BM microenvironment, BMSCs may contribute to the increase of $\mathrm{CD} 11 \mathrm{~b}^{+} \mathrm{LyG}^{\text {low }}$ cells and enhancement of immunosuppression through exosome secretion during MM progression.

Most of the factors that induce MDSC activation trigger STAT signaling pathways, including STAT3,
A

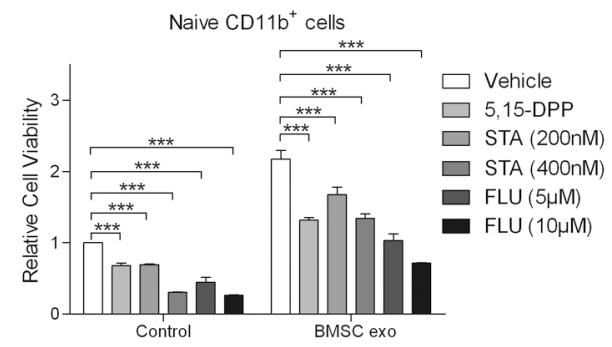

B

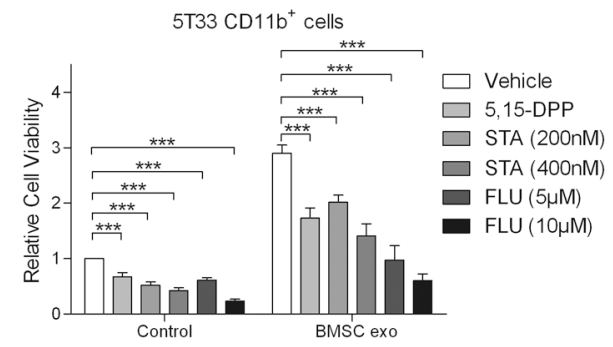

E

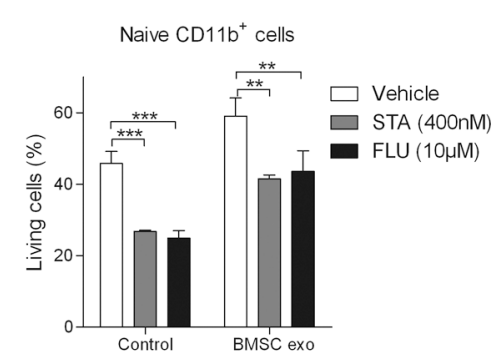

D
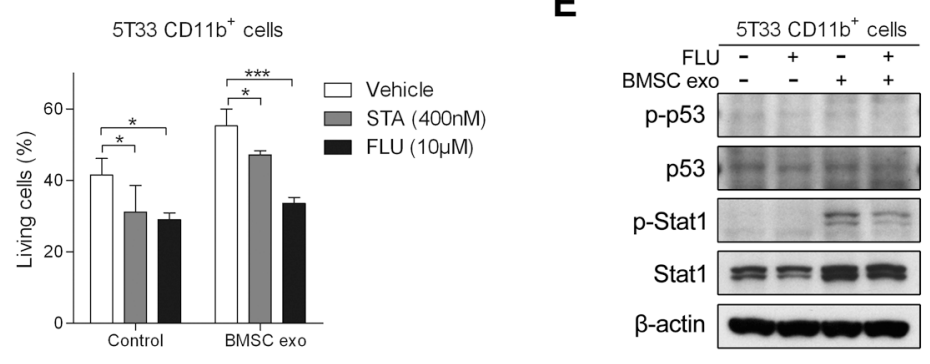

Figure 6: Inhibitors of STAT1 and STAT3 pathways suppress BMSC exosomes-induced survival of CD11 ${ }^{+}$cells. A. Naive $(n=3)$ or B. 5 T33 CD11 $\mathrm{b}^{+}$cells $(n=3)$ in $5 \%$ serum medium were cultured with or without BMSC exosomes $(100 \mu \mathrm{g} / \mathrm{ml})$ in the absence or presence of 5, 15-DPP, stattic (STA), or fludarabine (FLU) for 48 hours and the cell viability was determined by a luminescent viability assay. C. Naive $(n=3)$ or D. $5 \mathrm{~T} 33 \mathrm{CD} 11 \mathrm{~b}^{+}$cells $(n=3)$ in $5 \%$ serum medium were cultured with or without BMSC exosomes in the absence or presence of STA or FLU for 48 hours and living (Annexin V-) cells were determined by flow cytometry after Annexin V-FITC staining. E. 5T33 CD11b cells in 5\% serum medium were cultured with or without BMSC exosomes in the absence or presence of FLU $(10 \mu \mathrm{M})$ for 24 hours and phosphorylation of p53 and Stat1 (p-p53 and p-Stat1), as well as p53 and Stat1 were detected by western blot. $\beta$-actin protein was included as a loading control. * $=p<0.05, * *=p<0.01, * * *=p<0.001$. 
STAT6, and STAT1, to induce cell survival, proliferation, differentiation, and expansion of MDSC [28, 40-42]. Exosomes derived from mouse tumor cells could enhance the suppressive activity of MDSCs via the STAT3 pathways [29]. STAT1 is a transcription factor which is involved in the upregulation of immune suppressive factors by MDSCs upon stimulation of IFN- $\gamma$. Moreover, Stat $1^{-/}$ mice are not able to increase these factors and therefore can not inhibit $\mathrm{T}$ cell functions [43]. In our work, BMSC exosomes increased the activation of Stat1 and Stat3 in MDSCs from both naive and 5T33MM mice, suggesting a potential role of these exosomes in immunosuppression. In addition, pro-survival proteins Bcl-xL and $\mathrm{Mcl}-1$ were also elevated by BMSC exosomes. By using inhibitors for STAT3 and STAT1 pathways, BMSC exosome-mediated MDSC survival was significantly inhibited, confirming the involvement of these pathways in exosome-induced cell survival. However, since control conditions were
A

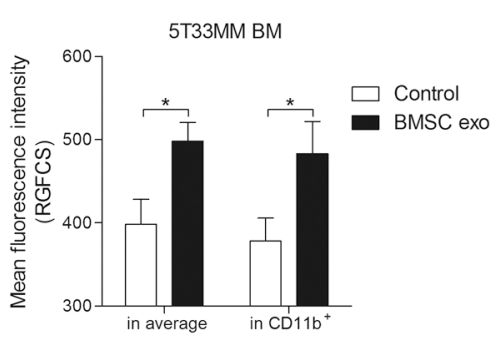

D

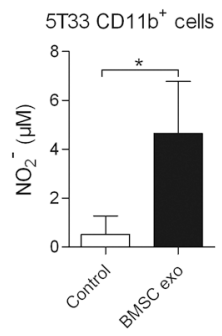

B

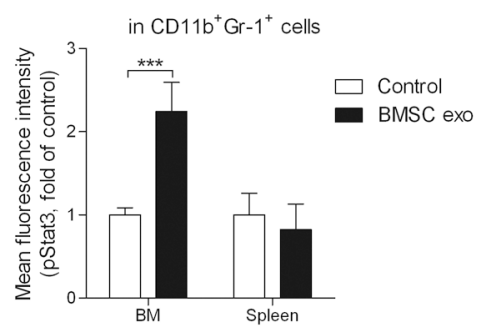

C

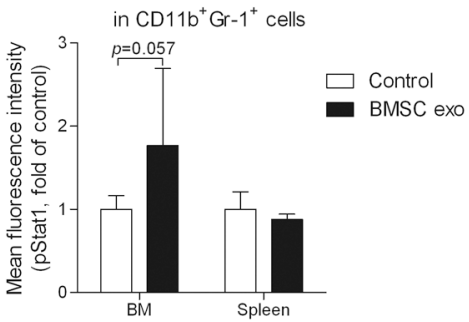

E

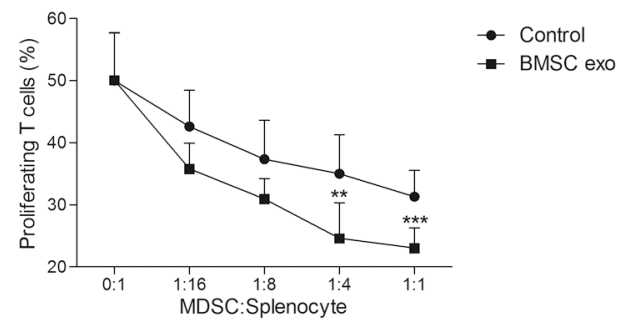

Figure 7: BMSC exosomes activate MDSCs in vivo and enhance their capability of T cell suppression. A. $200 \mu \mathrm{g}$ RGFCSlabeled BMSC exosomes (BMSC exo) or RGFCS control were intravenously injected into week 25 T33MM mice $(n=3)$ for 24 hours. The $\mathrm{BM}$ cells were isolated and stained with anti-CD11b-PE-Cy7. Mean florescence intensities of RGFCS in the total BM cells (in average)

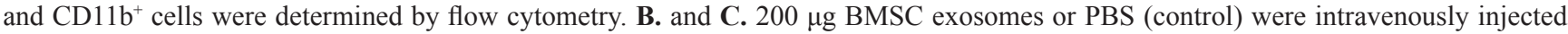
into week 2 5T33MM mice $(n=4)$ for 24 hours. Thereafter, the bone marrow and spleen cells were isolated and stained with anti-CD11bPE-Cy7, anti-Gr-1-APC, anti-p-Stat3-Alexa Fluor 488, and anti-p-Stat1-PE. Mean fluorescence intensities of (B) p-Stat3 or (C) p-Stat1 in $\mathrm{CD} 11 \mathrm{~b}^{+} \mathrm{Gr}-1^{+}$cells were measured by flow cytometry. D. CD11 ${ }^{+}$cells isolated from 5T33MM mice $(n=3)$ were cultured with BMSC exosomes for 48 hours and the concentration of NO in supernatant was measured. E. Splenocytes obtained from naive mice were labeled with CFSE, stimulated with CD3/CD28 Dynabeads, and cultured with indicated ratio of CD11 $\mathrm{b}^{+}$cells obtained from week 2 5T33MM mice $(n=8)$ intravenously injected with PBS (control) or $200 \mu \mathrm{g}$ BMSC exosomes. After 3 days of culture, the cells were stained with anti-CD3-PE-Cy7 and 7-AAD and the percentage of proliferating cells within gated CD3 ${ }^{+} 7-\mathrm{AAD}^{-}$cells was determined by flow cytometry. $*=p<0.05, * *=p<0.01, * * *=p<0.001$.

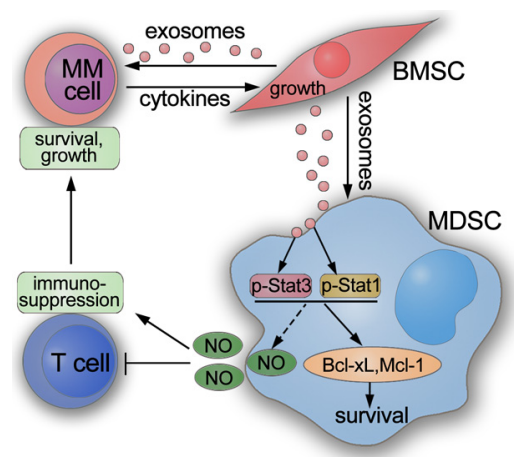

Figure 8: Schematic showing how BMSC exosomes indirectly favor MM cells through activating MDSCs. 
also affected by these inhibitors, we cannot rule out the involvement of other pathways. A recent study has shown that MDSC could directly mediate MM cell growth through PD1/PD-L1 signaling [44], therefore increased survival of MDSC through BMSC exosomes may directly affect MM cell growth.

It has been suggested that the expansion and activation of MDSCs is influenced by different factors produced by tumor cells, activated $\mathrm{T}$ cells, and tumor stromal cells [28]. Matrix metalloproteinase-9 (MMP9), MMP-8, and IL-8 produced by stromal cells in solid tumors facilitate MDSC expansion and human bone marrow MSCs also mediate expansion of MDSCs via hepatocyte growth factor (HGF) [24, 45, 46]. Extensive evidence has confirmed GM-CSF as an efficient stimulator for the immunosuppressive activity of MDSC and blocking the GM-CSF receptor blunts MDSC activation and expansion $[25,47,48]$. Neutralization of the binding between Hsp70 on the membrane of exosomes derived from solid tumors and MDSCs also abrogates exosomeinduced MDSC activation [29]. However, in our system, increase in MDSC cell viability induced by BMSC exosomes was not influenced by neutralizing antibodies for GM-CSF and Hsp70, implying the lack of involvement of GM-CSF and Hsp-70 in this cross talk, underscoring the difference between the exosomes derived from tumor cell and BMSC. Since BMSCs can promote MM cell growth through secretion of cytokines such as vascular endothelial growth factor, IL-6, and HGF [20], which have also been suggested to be involved in MDSC activation [49], it is possible that these factors play a role in BMSC exosome stimulation.

Activated MDSC suppress T cell function mainly through two mechanisms: direct cell-cell contact and secretion of soluble mediators [28]. Increased NO production is commonly observed after MDSC activation $[39,50]$ and MDSC induce $\mathrm{T}$ cell suppression through various mechanisms that involve the inhibition of $\mathrm{MHC}$ class II expression [51] and induction of T cell apoptosis [52]. Here, we show for the first time that BMSC exosomes induced more production of NO from 5T33MM BM MDSC and that they enhanced the T cell suppressive capacity of MDSCs in vivo. Our data, together with other studies showing that increased NO production induces suppression of $\mathrm{T}$ cell proliferation $[28,53]$, suggest that BMSC exosomes enhance immunosuppression through promoting NO release in MDSCs. Also, our group has shown that T-cell suppression by Ly6G ${ }^{\text {low }}$ MDSCs was partially mediated through NO [31]. Moreover, an increase in the number of MDSCs induced by BMSC exosomes may also contribute to the enhancement of suppression through cell-cell contact.

In conclusion, BMSC exosomes not only directly promote MM survival but also indirectly favor MM progression through enhancing the immunosuppressive activity of MDSC in the BM. Our findings not only address the role of BMSC exosomes in the BM microenvironment but also expand the understanding of the participation of these exosomes in MM progression. Moreover, our results strengthen the usefulness of STAT inhibitors in MM treatment through targeting of MDSC activation.

\section{MATERIALS AND METHODS}

\section{Mice and 5T33MM model}

C57BL/KaLwRij mice used in this study were purchased from Harlan Laboratories (Horst, The Netherlands). The 5T33MM model is propagated by intravenous injection of diseased MM BM cells into 8-10 weeks female naive C57BL/KaLwRij mice. All the mice were housed and treated following conditions approved by the Ethical Committee for Animal Experiments of the Vrije Universiteit Brussel (license no. LA1230281).

\section{Cell culture, blocking antibodies, and reagents}

Primary BMSCs were isolated from diseased 5T33MM mice and maintained in DMEM medium (Lonza, Visp, Switzerland) supplemented with 10\% fetal calf serum (HyClone, Logan, UT, USA), 10\% horse serum (Invitrogen, Carlsbad, CA, USA), $100 \mathrm{U} / \mathrm{mL}$ penicillin/streptomycin and $2 \mathrm{mM}$ L-glutamine (Lonza). BMSCs were used at the second to tenth passage without mycoplasma contamination. Anti-mouse GM-CSF (16$7331)$ and $\operatorname{IgG}$ isotype control (16-4321) were bought from eBioscience (San Diego, CA USA). Anti-Hsp70 (MA3-009) was purchased from Thermo Scientific (Rockford, IL, USA). The lipophilic tracer DIO and SYTO RNASelect green fluorescent cell stain (RGFCS) were purchased from Life Technologies (Carlsbad, CA, USA). 5, 15-DPP was purchased from Sigma (St Louis, MO, USA). Stattic and fludarabine were bought from Selleckchem (Houston, TX, USA).

\section{Exosome isolation}

Exosome were isolated from conditioned medium as previously described [11], but with a small modification. Briefly, BMSCs were cultured without serum for 48 hours and conditioned medium was filtered using $0.22-\mu \mathrm{m}$ pore filter. Pierce protein concentrator (150KD) (Thermo Scientific) was used to concentrate the filtered medium and to remove the soluble proteins (less than $150 \mathrm{kD}$ ), as well as smaller particles (less than $\sim 15 \mathrm{~nm}$ ). Concentrated medium were filtered with $0.22-\mu \mathrm{m}$ pore filter again and incubated with ExoQuick-TC exosome precipitation solution (System Biosciences, Mountain View, CA, USA) at $4{ }^{\circ} \mathrm{C}$ overnight. Exosomes were subsequently pelleted by centrifugation at $1,500 \mathrm{~g}$ for 30 minutes and suspended in PBS or serum-free medium. Protein quantification was performed as previously described [11]. 


\section{Fluorescent labeling of exosomes}

Exosome suspension was incubated with DIO cell-labeling solution for 30 minutes at $37^{\circ} \mathrm{C}$ according to the manufacturer's instruction and exosomes were reprecipitated using ExoQuick-TC exosome precipitation solution. DIO-containing medium without exosomes was used as a procedure control. For RGFCS staining, exosome suspension or medium without exosomes (control) were incubated with RGFCS $(10 \mu \mathrm{M})$ at $37^{\circ} \mathrm{C}$ for 30 minutes. An Exosome Spin Column (Life Technologies) was used to remove the unincorporated DIO or RGFCS from the labeled exosomes. DIO or RGFCS control solutions were also processed using Exosome Spin Columns and the flow-through was collected and used as a parallel control.

\section{Flow cytometry}

For staining the membrane antigens of BM cells, single-cell suspension was prepared. After treatment with exosomes, $1 \times 10^{6}$ cells were resuspended in PBS with 5\% BSA and stained with PE-Cy7-conjugated antibodies to CD11b (anti-CD11b-PE-Cy7, 101216, BioLegend, San Diego, CA, USA) and with 3H2, an anti-idiotype antibody against 5T33MM cells [54], followed by an APC-conjugated rat anti mouse IgG1 (550874, BD Biosciences, San Jose, CA, USA). For staining the membrane markers of MDSCs, the cells were stained with anti-Gr-1-APC (17-5931, eBioscience) and anti-CD11b-PE-Cy7 or with antiLy6G-PE-Cy7 (127618, BioLegend) and anti-Ly6CAPC (560595, BD Biosciences). Staining with Annexin V-fluorescein isothiocyanate (Annexin V-FITC, 556419, BD Biosciences) was used to determine the apoptotic cells. For staining intracellular p-Stat 3 and p-Stat 1 in MDSCs, cells were first fixed with formaldehyde and methanol, followed by staining with anti-Gr-1APC, anti-CD11b-PE-Cy7, anti-p-Stat3-Alexa Fluor 488 (557814, BD Biosciences), and anti-p-Stat1PE (612564, BD Biosciences). The percentage of a certain population and mean fluorescence intensity was evaluated using a FACSCanto flow cytometer (BD Biosciences) and Flowjo software (TreeStar, Ashland, OR, USA).

\section{Magnetic-activated cell sorting (MACS) for CD11b $^{+}$cells}

After removing red blood cells, BM cells obtained from naive or $5 \mathrm{~T} 33 \mathrm{MM}$ mice were incubated with CD11b Microbeads (Miltenyi Biotec, Bergisch Gladbach, Germany) for 15 minutes at $4^{\circ} \mathrm{C}$. $\mathrm{CD} 11 \mathrm{~b}^{+}$cells were then separated using LS Columns (Miltenyi Biotec) and MACS separator (Miltenyi Biotec) according to the manufacturer's instruction. The purity of $\mathrm{CD}_{11 \mathrm{~b}^{+} \text {cells }}$ was determined using flow cytometry after staining with anti-CD11b-PE-Cy7.

\section{Cell viability and cell apoptosis assays}

$5 \times 10^{4}$ sorted naive or $5 \mathrm{~T} 33 \mathrm{MM} \mathrm{CD} 11 \mathrm{~b}^{+}$cells were treated with or without BMSC-derived exosomes in the absence or presence of indicated inhibitors for 24 or 48 hours. Then, cell viability was measured by Cell Titer glo Luminescent Viability assay (Promega, Madison, WI, USA) according to the manufacturer's instructions. For the cell apoptosis assay, $5 \times 10^{5} \mathrm{CD}_{11 \mathrm{~b}^{+}}$cells were seeded in a 24-well plate and treated with exosomes and inhibitors. Apoptotic cells were determined using flow cytometry after Annexin V-FITC staining.

\section{Western blot}

Western blot was performed as described previously [11] and antibodies for $\beta$-actin (4967), Bcl-xL (2764), Mcl-1 (5453), Stat1 (9172), p-Stat1 (Tyr701) (9167), Stat3 (4904), p-Stat3 (Tyr705) (9138), p-p53 (9281) and p53 (2524) as well as horseradish peroxidase (HRP)-linked anti-mouse (7076) and -rabbit (7074) IgG, purchased from Cell Signaling Technology (Bioké, Leiden, The Netherlands) were used.

\section{Nitric oxide (NO) measurement}

$\mathrm{CD} 11 \mathrm{~b}^{+}$cells $\left(3 \times 10^{6} / \mathrm{ml}\right)$ isolated from $5 \mathrm{~T} 33 \mathrm{MM}$ $\mathrm{BM}$ were cultured with exosomes for 48 hours and the supernatants were collected for NO measurement. NO was measured as nitrite using a Griess reagent kit (Life Technologies) according to the manufacturer's instruction. Briefly, $130 \mu \mathrm{l}$ Milli-Q water was mixed with $20 \mu \mathrm{l}$ of mixture solution containing sulfanilic acid and N-(1naphthyl) ethylenediamine dihydrochloride, followed by adding $150 \mu \mathrm{l}$ culture supernatant. After 30 minutes incubation, absorbance was measured at $540 \mathrm{~nm}$ in a spectrophotometric microplate reader.

\section{In vivo study}

Mice were inoculated with $5 \times 10^{5} 5 \mathrm{~T} 33 \mathrm{MM}$ cells and after 2 weeks, they were randomly divided and intravenously injected with $200 \mu \mathrm{g}$ BMSC exosomes or PBS. After 24 hours, the total BM and spleen cells were isolated and the levels of p-Stat 1 and p-Stat 3 in $\mathrm{CD} 11 \mathrm{~b}^{+} \mathrm{GR}-1^{+}$cells were measured using flow cytometry. $\mathrm{CD}_{11 \mathrm{~b}^{+}}$cells were sorted from these BM cells using MACS and the immunosuppressive capacity of these cells was determined using $\mathrm{T}$ cell proliferation assay.

\section{$T$ cell proliferation assay}

Splenocytes were isolated from naive mice and stained with CFSE after removing red blood cells. CFSElabeled cells were cultured with RPMI1640 medium supplemented with 10\% HEPES (Sigma) and $20 \mu \mathrm{M}$ $\beta$-mercaptoethanol (Sigma) for 20-30 minutes. Then, they were seeded into a 96 -well plate $\left(1 \times 10^{5}\right.$ cells/ 
well) and stimulated with CD3/CD28 Dynabeads (Life Technologies). $\mathrm{CD} 11 \mathrm{~b}^{+}$cells obtained from week 2 5T33MM mice injected with PBS or BMSC exosomes were added to splenocytes at multiple ratios and cultured for 3 days. All the cells were stained with anti-CD3-PECy7 (100220, BioLegend), 7-amino-actinomycin D (7AAD, BD Biosciences) and proliferation of living T cells ( $\mathrm{CD}^{+}{ }^{+}$-AAD ${ }^{-}$cells) was determined with $\mathrm{CFSE}$ dilution by flow cytometry.

\section{Statistical analysis}

Results were analyzed with Graphpad prism 5 software. Mann-Whitney test or One-way ANOVA was used to determine the statistical significance. Error bars represent mean \pm standard deviation (S.D.). $p<0.05$ was regarded as statistically significant.

\section{ACKNOWLEDGMENTS}

The authors thank Carin Seynaeve and Sofie Seghers for expert technical assistance. This work was supported by fonds voor wetenschappelijk onderzoek (FWO-VI). J. Wang was supported by a China Scholarship Council (CSC)-VUB scholarship. K. De Veirman was supported by OVER-MyR. N. De Beule is a PhD student supported from FWO-VI. E. Menu is a postdoctoral fellow of AXA Research Fund. K. Maes, E. Van Valckenborgh and E. De Bruyne are postdoctoral fellows of FWO-VI. This work was published with the support of the University Foundation Belgium.

\section{CONFLICTS OF INTEREST}

The authors declare no conflict of interest.

\section{REFERENCE}

1. Thery C, Ostrowski M and Segura E. Membrane vesicles as conveyors of immune responses. Nat Rev Immunol. 2009; 9:581-593.

2. Raposo G and Stoorvogel W. Extracellular vesicles: exosomes, microvesicles, and friends. J Cell Biol. 2013; 200:373-383.

3. Marton A, Vizler C, Kusz E, Temesfoi V, Szathmary Z, Nagy K, Szegletes Z, Varo G, Siklos L, Katona RL, Tubak V, Howard OM, Duda E, Minarovits J and Buzas K. Melanoma cell-derived exosomes alter macrophage and dendritic cell functions in vitro. Immunol Lett. 2012; 148:34-38.

4. Naslund TI, Gehrmann U, Qazi KR, Karlsson MC and Gabrielsson S. Dendritic cell-derived exosomes need to activate both $\mathrm{T}$ and $\mathrm{B}$ cells to induce antitumor immunity. J Immunol. 2013; 190:2712-2719.

5. Yang C, Chalasani G, Ng YH and Robbins PD. Exosomes released from Mycoplasma infected tumor cells activate inhibitory B cells. PLoS One. 2012; 7:e36138.
6. Abusamra AJ, Zhong Z, Zheng X, Li M, Ichim TE, Chin $\mathrm{JL}$ and Min WP. Tumor exosomes expressing Fas ligand mediate CD8+ T-cell apoptosis. Blood Cells Mol Dis. 2005; 35:169-173.

7. Chowdhury R, Webber JP, Gurney M, Mason MD, Tabi Z and Clayton A. Cancer exosomes trigger mesenchymal stem cell differentiation into pro-angiogenic and pro-invasive myofibroblasts. Oncotarget. 2015; 6:715-731.

8. Corrado C, Raimondo S, Saieva L, Flugy AM, De Leo G and Alessandro R. Exosome-mediated crosstalk between chronic myelogenous leukemia cells and human bone marrow stromal cells triggers an interleukin 8-dependent survival of leukemia cells. Cancer Lett. 2014; 348:71-76.

9. Liu Y, Xiang X, Zhuang X, Zhang S, Liu C, Cheng Z, Michalek S, Grizzle W and Zhang HG. Contribution of MyD88 to the tumor exosome-mediated induction of myeloid derived suppressor cells. Am J Pathol. 2010; 176:2490-2499.

10. Xiang X, Poliakov A, Liu C, Liu Y, Deng ZB, Wang J, Cheng Z, Shah SV, Wang GJ, Zhang L, Grizzle WE, Mobley $\mathrm{J}$ and Zhang HG. Induction of myeloid-derived suppressor cells by tumor exosomes. Int J Cancer. 2009; 124:2621-2633.

11. Wang J, Hendrix A, Hernot S, Lemaire M, De Bruyne E, Van Valckenborgh E, Lahoutte T, De Wever O, Vanderkerken $\mathrm{K}$ and Menu E. Bone marrow stromal cellderived exosomes as communicators in drug resistance in multiple myeloma cells. Blood. 2014; 124:555-566.

12. Bian S, Zhang L, Duan L, Wang X, Min Y and Yu H. Extracellular vesicles derived from human bone marrow mesenchymal stem cells promote angiogenesis in a rat myocardial infarction model. J Mol Med (Berl). 2014; 92:387-397.

13. Tadokoro H, Umezu $\mathrm{T}$, Ohyashiki $\mathrm{K}$, Hirano $\mathrm{T}$ and Ohyashiki JH. Exosomes derived from hypoxic leukemia cells enhance tube formation in endothelial cells. J Biol Chem. 2013; 288:34343-34351.

14. Umezu T, Tadokoro H, Azuma K, Yoshizawa S, Ohyashiki $\mathrm{K}$ and Ohyashiki JH. Exosomal miR-135b shed from hypoxic multiple myeloma cells enhances angiogenesis by targeting factor-inhibiting HIF-1. Blood. 2014; 124:3748-3757.

15. Yu S, Liu C, Su K, Wang J, Liu Y, Zhang L, Li C, Cong Y, Kimberly R, Grizzle WE, Falkson C and Zhang HG. Tumor exosomes inhibit differentiation of bone marrow dendritic cells. J Immunol. 2007; 178:6867-6875.

16. Singh PP, Smith VL, Karakousis PC and Schorey JS. Exosomes isolated from mycobacteria-infected mice or cultured macrophages can recruit and activate immune cells in vitro and in vivo. J Immunol. 2012; 189:777-785.

17. Kim SH, Lechman ER, Bianco N, Menon R, Keravala A, Nash J, Mi Z, Watkins SC, Gambotto A and Robbins PD. Exosomes derived from IL-10-treated dendritic cells can suppress inflammation and collagen-induced arthritis. J Immunol. 2005; 174:6440-6448. 
18. Peinado H, Aleckovic M, Lavotshkin S, Matei I, CostaSilva B, Moreno-Bueno G, Hergueta-Redondo M, Williams C, Garcia-Santos G, Ghajar C, Nitadori-Hoshino A, Hoffman C, Badal K, Garcia BA, Callahan MK, Yuan J, et al. Melanoma exosomes educate bone marrow progenitor cells toward a pro-metastatic phenotype through MET. Nat Med. 2012; 18:883-891.

19. Lemaire M, Deleu S, De Bruyne E, Van Valckenborgh E, Menu E and Vanderkerken K. The microenvironment and molecular biology of the multiple myeloma tumor. Adv Cancer Res. 2011; 110:19-42.

20. Mahindra A, Hideshima $\mathrm{T}$ and Anderson KC. Multiple myeloma: biology of the disease. Blood Rev. 2010; 24 Suppl 1:S5-11.

21. Bassi EJ, Aita CA and Camara NO. Immune regulatory properties of multipotent mesenchymal stromal cells: Where do we stand? World J Stem Cells. 2011; 3:1-8.

22. Vasold J, Wagner M, Drolle H, Deniffel C, Kutt A, Oostendorp R, Sironi S, Rieger C and Fiegl M. The bone marrow microenvironment is a critical player in the NK cell response against acute myeloid leukaemia in vitro. Leuk Res. 2015; 39:257-262.

23. Ricciardi M, Malpeli G, Bifari F, Bassi G, Pacelli L, Nwabo Kamdje AH, Chilosi M and Krampera M. Comparison of epithelial differentiation and immune regulatory properties of mesenchymal stromal cells derived from human lung and bone marrow. PLoS One. 2012; 7:e35639.

24. Yen BL, Yen ML, Hsu PJ, Liu KJ, Wang CJ, Bai CH and Sytwu HK. Multipotent human mesenchymal stromal cells mediate expansion of myeloid-derived suppressor cells via hepatocyte growth factor/c-met and STAT3. Stem Cell Reports. 2013; 1:139-151.

25. De Veirman K, Van Ginderachter JA, Lub S, De Beule N, Thielemans K, Bautmans I, Oyajobi BO, De Bruyne E, Menu E, Lemaire M, Van Riet I, Vanderkerken K and Van Valckenborgh E. Multiple myeloma induces Mcl-1 expression and survival of myeloid-derived suppressor cells. Oncotarget. 2015; 6:10532-47.

26. De Veirman K, Van Valckenborgh E, Lahmar Q, Geeraerts X, De Bruyne E, Menu E, Van Riet I, Vanderkerken K and Van Ginderachter JA. Myeloid-derived suppressor cells as therapeutic target in hematological malignancies. Front Oncol. 2014; 4:349.

27. Scarlett CJ. Contribution of bone marrow derived cells to the pancreatic tumor microenvironment. Front Physiol. 2013; 4:56.

28. Gabrilovich DI and Nagaraj S. Myeloid-derived suppressor cells as regulators of the immune system. Nat Rev Immunol. 2009; 9:162-174.

29. Chalmin F, Ladoire S, Mignot G, Vincent J, Bruchard M, Remy-Martin JP, Boireau W, Rouleau A, Simon B, Lanneau D, De Thonel A, Multhoff G, Hamman A, Martin F, Chauffert B, Solary E, et al. Membrane-associated Hsp72 from tumor-derived exosomes mediates STAT3dependent immunosuppressive function of mouse and human myeloid-derived suppressor cells. J Clin Invest. 2010; 120:457-471.

30. Ramachandran IR, Martner A, Pisklakova A, Condamine T, Chase T, Vogl T, Roth J, Gabrilovich D and Nefedova Y. Myeloid-derived suppressor cells regulate growth of multiple myeloma by inhibiting $\mathrm{T}$ cells in bone marrow. J Immunol. 2013; 190:3815-3823.

31. Van Valckenborgh E, Schouppe E, Movahedi K, De Bruyne E, Menu E, De Baetselier P, Vanderkerken K and Van Ginderachter JA. Multiple myeloma induces the immunosuppressive capacity of distinct myeloid-derived suppressor cell subpopulations in the bone marrow. Leukemia. 2012; 26:2424-2428.

32. Gorgun GT, Whitehill G, Anderson JL, Hideshima T, Maguire C, Laubach J, Raje N, Munshi NC, Richardson PG and Anderson KC. Tumor-promoting immune-suppressive myeloid-derived suppressor cells in the multiple myeloma microenvironment in humans. Blood. 2013; 121:2975-2987.

33. Roccaro AM, Sacco A, Maiso P, Azab AK, Tai YT, Reagan M, Azab F, Flores LM, Campigotto F, Weller E, Anderson $\mathrm{KC}$, Scadden DT and Ghobrial IM. BM mesenchymal stromal cell-derived exosomes facilitate multiple myeloma progression. J Clin Invest. 2013; 123:1542-1555.

34. Ochando JC and Chen SH. Myeloid-derived suppressor cells in transplantation and cancer. Immunol Res. 2012; 54:275-285.

35. Chaudhuri A, Yang B, Gendelman HE, Persidsky Y and Kanmogne GD. STAT1 signaling modulates HIV-1induced inflammatory responses and leukocyte transmigration across the blood-brain barrier. Blood. 2008; 111:2062-2072.

36. Frank DA, Mahajan S and Ritz J. Fludarabine-induced immunosuppression is associated with inhibition of STAT1 signaling. Nat Med. 1999; 5:444-447.

37. Rosenwald A, Chuang EY, Davis RE, Wiestner A, Alizadeh AA, Arthur DC, Mitchell JB, Marti GE, Fowler DH, Wilson WH and Staudt LM. Fludarabine treatment of patients with chronic lymphocytic leukemia induces a p53-dependent gene expression response. Blood. 2004; 104:1428-1434.

38. Zhu B, Bando Y, Xiao S, Yang K, Anderson AC, Kuchroo VK and Khoury SJ. CD11b+Ly-6C(hi) suppressive monocytes in experimental autoimmune encephalomyelitis. J Immunol. 2007; 179:5228-5237.

39. Movahedi K, Guilliams M, Van den Bossche J, Van den Bergh R, Gysemans C, Beschin A, De Baetselier P and Van Ginderachter JA. Identification of discrete tumorinduced myeloid-derived suppressor cell subpopulations with distinct $\mathrm{T}$ cell-suppressive activity. Blood. 2008; 111:4233-4244.

40. Lee CK, Smith E, Gimeno R, Gertner R and Levy DE. STAT1 affects lymphocyte survival and proliferation partially independent of its role downstream of IFN-gamma. J Immunol. 2000; 164:1286-1292.

41. Baus D, Nonnenmacher F, Jankowski S, Doring C, Brautigam C, Frank M, Hansmann ML and Pfitzner E. 
STAT6 and STAT1 are essential antagonistic regulators of cell survival in classical Hodgkin lymphoma cell line. Leukemia. 2009; 23:1885-1893.

42. Hirano T, Ishihara K and Hibi M. Roles of STAT3 in mediating the cell growth, differentiation and survival signals relayed through the IL-6 family of cytokine receptors. Oncogene. 2000; 19:2548-2556.

43. Kusmartsev S and Gabrilovich DI. STAT1 signaling regulates tumor-associated macrophage-mediated T cell deletion. J Immunol. 2005; 174:4880-4891.

44. Gorgun G, Samur MK, Cowens KB, Paula S, Bianchi G, Anderson JE, White RE, Singh A, Ohguchi H, Suzuki R, Kikuchi S, Harada T, Hideshima T, Tai YT, Laubach JP, Raje NS, et al. Lenalidomide Enhances Immune Checkpoint Blockade Induced Immune Response in Multiple Myeloma. Clin Cancer Res. 2015.

45. Melani C, Sangaletti S, Barazzetta FM, Werb Z and Colombo MP. Amino-biphosphonate-mediated MMP-9 inhibition breaks the tumor-bone marrow axis responsible for myeloid-derived suppressor cell expansion and macrophage infiltration in tumor stroma. Cancer Res. 2007; 67:11438-11446.

46. Finke J, Ko J, Rini B, Rayman P, Ireland J and Cohen P. MDSC as a mechanism of tumor escape from sunitinib mediated anti-angiogenic therapy. Int Immunopharmacol. 2011; 11:856-861.

47. Kapanadze T, Gamrekelashvili J, Ma C, Chan C, Zhao F, Hewitt S, Zender L, Kapoor V, Felsher DW, Manns MP, Korangy $\mathrm{F}$ and Greten TF. Regulation of accumulation and function of myeloid derived suppressor cells in different murine models of hepatocellular carcinoma. J Hepatol. 2013; 59:1007-1013.

48. Parekh VV, Wu L, Olivares-Villagomez D, Wilson KT and Van Kaer L. Activated invariant NKT cells control central nervous system autoimmunity in a mechanism that involves myeloid-derived suppressor cells. J Immunol. 2013; 190:1948-1960.

49. Botta C, Gulla A, Correale P, Tagliaferri P and Tassone P. Myeloid-derived suppressor cells in multiple myeloma: pre-clinical research and translational opportunities. Front Oncol. 2014; 4:348.

50. Nagaraj S and Gabrilovich DI. Myeloid-derived suppressor cells in human cancer. Cancer J. 2010; 16:348-353.

51. Harari $\mathrm{O}$ and Liao JK. Inhibition of MHC II gene transcription by nitric oxide and antioxidants. Curr Pharm Des. 2004; 10:893-898.

52. Rivoltini L, Carrabba M, Huber V, Castelli C, Novellino L, Dalerba P, Mortarini R, Arancia G, Anichini A, Fais S and Parmiani G. Immunity to cancer: attack and escape in T lymphocyte-tumor cell interaction. Immunol Rev. 2002; 188:97-113.

53. Sato K, Ozaki K, Oh I, Meguro A, Hatanaka K, Nagai T, Muroi K and Ozawa K. Nitric oxide plays a critical role in suppression of T-cell proliferation by mesenchymal stem cells. Blood. 2007; 109:228-234.

54. Vanderkerken K, De Raeve H, Goes E, Van Meirvenne S, Radl J, Van Riet I, Thielemans K and Van Camp B. Organ involvement and phenotypic adhesion profile of 5T2 and 5T33 myeloma cells in the C57BL/KaLwRij mouse. Br J Cancer. 1997; 76:451-460. 